Sharif University of Technology
Scientia Iranica
Transactions E: Industrial Engineering
wCIENTIA

\title{
Pricing and ordering under trade promotion, brand competition, and demand uncertainty
}

\author{
Y.-C. Tsao* \\ Department of Industrial Management, National Taiwan University of Science and Technology, Taipei, Taiwan.
}

Received 17 May 2015; received in revised form 23 July 2015; accepted 15 September 2015

\section{KEYWORDS}

Pricing;

Inventory;

Brand competition;

Demand uncertainty;

Piecewise nonlinear.

\begin{abstract}
In practice, many manufacturers offer trade promotion to retailers to induce demand. It is also common for a retailer to sell products of competing manufacturers. This paper considers a two-echelon supply chain where two manufacturers provide a trade promotion to a retailer, and the retailer faces uncertain and price-dependent demand. In the model, the manufacturers determine wholesale prices and the retailer determines retail price and order quantity to maximize their own profits. An algorithm based on non-linear optimization is provided to solve the problem. We compare three trade promotions under brand competition: off-invoice, scan-back, and buy-back policies, and discuss the effects of trade promotions on decisions and profits. The results indicate that the manufacturers and retailer prefer the buy-back policy over the off-invoice and scan-back policies. The retailer's profit will increase and the manufacturers' profits will decrease as the brand substitution effect increases. Also, the manufacturers will raise their wholesale prices, but the retailer will reduce the retail price and order quantity when the brand substitution rate increases.
\end{abstract}

(C) 2016 Sharif University of Technology. All rights reserved.

\section{Introduction}

Price is one of the major strategy decision variables that a company controls. Pricing decisions affect not only the number of sales a company makes, but also how much money it earns. In practice, determining the optimal price to maximize the company's profit under demand uncertainty is challenging for managers. In academia, pricing is incorporated into the inventory models under different situations. Making price and inventory decisions simultaneously is becoming an important issue in today's business.

Tsao et al. [1] and Modak et al. [2] emphasized the importance of integrated pricing and lot-size decisionmaking. Ouyang et al. [3] developed an optimization approach for joint pricing and ordering problem under order-size dependent trade credit. Sajadieh and

\footnotetext{
*. Tel.: +886-2-27303624; Fax: +886-2-22830713

E-mail address: yctsao@mail.ntust.edu.tw
}

Jokar. [4] made the optimal pricing, ordering, and shipment decisions in a two-stage supply chain with pricesensitive demand. Sana [5] developed stochastic EOQ model with random sales price. Cai et al. [6] studied the optimal pricing and ordering with partial lost sales in two-stage supply chains. Sana [7] determined the optimal production rate, order quantity, number of shipments with equal sizes. Hsieh et al. [8] considered multiple manufacturers and a common retailer in a supply chain facing uncertain demand. Maihami and Karimi [9] optimized the pricing and replenishment policy for non-instantaneous deteriorating items with stochastic demand and promotional efforts. Modak et al. [10] explored channel coordination and profit division issues of a manufacturer-distributer-duopolistic retailers supply chain. Panda et al. [11] and Modak et al. [12] considered joint decisions in dual-channel supply chains.

Trade promotions are designed to influence endcustomer demand by providing various inducements 
from manufacturers to retailers, which is a crucial factor in achieving volume and profitable growth. In practice, many manufacturers offer trade promotion to retailers to induce demand. Trade promotions account for over $60 \%$ of manufacturer's marketing budgets for packaged goods [13] and for an unprecedented $18.01 \%$ of U.S. manufacturers' gross sales in 2010 [14]. Two commonly used trade promotions are off-invoice and scan-back policies. For the off-invoice policy, manufacturers offer discounts on the order quantity sold to retailers. For the scan-back policy, manufacturers offer discounts on the actual quantity that retailers sell to end customers. Due to the existence of trade promotion, it is important to consider trade promotions when developing two-echelon supply chain models.

In addition, buy-back is another commonly incentive policy in which a retailer is allowed to return unsold products to the manufacturer at an agreed price. For example, a buy-back agreement in a sales contract may require the builder-seller to buy the property back, if the buyer-occupant is transferred by his company within six months; it is commonly used in the publishing, home video, newspaper, and apparel industries. Blockbuster and its suppliers are a famous example to use buy-back policy to increase their revenues. Several studies considered the buy-back policy as a coordination contract to achieve channel coordination [15-18]. In our research, we consider it as a trade promotion policy and compare it with offinvoice and scan-back policies.

It is common for a retailer to sell products of competing manufacturers. A typical example is Procter \& Gamble's Crest toothpaste versus Colgate-Palmolive's Colgate toothpaste at a supermarket [19]. These firms want to know which trade promotion is best for them under brand competition and demand uncertainty. Thereby, we also consider the competition that arises because of brand substitution. This means that some customers may switch to another brand if their preferred brand is out-of-stock. Demand uncertainty is the major reason to cause a company to experience outof-stock event. In practice, customer demand can never be forecasted exactly. Treating consumer demand as uncertain and applying probability theory to help companies make decisions are important. Sana and Goyal [20] considered the stochastic demand with leadtime dependent partial backlogging. In this paper, we consider the pricing and ordering simultaneously under trade promotion, brand competition, and demand uncertainty.

The remainder of this paper is organized as follows: The models and the solution approach are presented in Section 2. In Section 3, the numerical analysis is conducted to get the managerial insights. Section 4 presents conclusions on managerial implications.

\section{Models}

In this paper, we use the following notations:

- $\alpha$ : Per-unit discount under the off-invoice policy;

- $P_{O, i}$ : Retail price for channel $i$ in the off-invoice case;

- $W_{O, i}$ : Wholesale price for channel $i$ in the off-invoice case;

- $Q_{O, i}$ : Retailer order quantity for channel $i$ in the off-invoice case;

- $\beta$ : Per-unit discount under the scan-back policy;

- $P_{S, i}$ : Retail price for channel $i$ in the scan-back case;

- $W_{S, i}$ : Wholesale price for channel $i$ in the scan-back case;

- $Q_{S, i}$ : Retailer order quantity for channel $i$ in the scan-back case;

- $B$ : Buy-back price per unsold unit under the buyback policy;

- $P_{B, i}$ : Retail price for channel $i$ in the buy-back case;

- $W_{B, i}$ : Wholesale price for channel $i$ in the buy-back case;

- $Q_{B, i}$ : Retailer order quantity for channel $i$ in the buy-back case;

- $D$ : Demand function, $D=f(p)+U$, where $f(p)=$ $a-b p$ is a function of unit retail price $p$ with $a>0$, and $b>0$, and $U$ is a continuous random variable following a uniform distribution on $[-(a-b p), a-b p]$;

- $\Pi_{M_{O . i}}$ : Manufacturer $i$ 's profit in the off-invoice case;

- $\Pi_{R_{0}}$ : Retailer's profit in the off-invoice case;

- $\Pi_{M_{S, i}}$ : Manufacturer $i$ 's profit in the scan-back case;

- $\Pi_{R_{S}}$ : Retailer's profit in the scan-back case;

- $\Pi_{M_{B, i}}$ : Manufacturer $i$ 's profit in the buy-back case;

- $\Pi_{R_{B}}$ : Retailer's profit in the buy-back case.

This paper considers that the brand competition arises because of brand substitution. That is, some customers may switch to another brand if their preferred brand is in shortage. We model a customer's willingness to buy another brand, when his preferred brand is out-of-stock by the parameter $\phi$ (i.e., the rate of brand substitution). In practice, factors, such as brand loyalty and searching cost, could determine the value $\phi$. In our models, two manufacturers (namely, manufacturer $i$ and manufacturer $j$ ) simultaneously offer the same trade promotion to the retailer. When the supply exceeds the demand in the channel of manufacturer $i$ (channel $i$ ), and shortages take place in channel $j$, some customers in channel $j$ will shift to channel $i$. We develop three models for off-invoice, 
scan-back, and buy-back trade promotion policies. We assume symmetric prices at the wholesale and retailer levels and trade promotions in each model to compare the three different trade promotions under brand competition.

When the off-invoice policy is used, the trade promotion discount, $\alpha$, is offered by the manufacturer as a price reduction on the normal price of goods. To consider the demand shifting from channel $j$ to channel $i$, we should compare two quantities. The first quantity is:

$$
\phi \int_{Q_{O, j}}^{2\left(a-b P_{O . j}\right)} \frac{u-Q_{O, j}}{2\left(a-b P_{O, j}\right)} d u,
$$

which is the expected amount of customer demand willing to shift from channel $j$ to channel $i$. The second quantity is:

$$
\int_{0}^{Q_{O, i}} \frac{Q_{O, i}-t}{2\left(a-b P_{O, i}\right)} d t
$$

which is the expected surplus supply quantity in channel $i$. When:

$$
\int_{0}^{Q_{O, i}} \frac{Q_{O, j}-t}{2\left(a-b P_{O, i}\right)} d t \geq \phi \int_{Q_{O, j}}^{2\left(a-b P_{O . j}\right)} \frac{u-Q_{O, j}}{2\left(a-b P_{O, j}\right)} d u
$$

the expected demand shift is:

$$
\phi \int_{0}^{Q_{O, i}} \int_{Q_{O, j}}^{2\left(a-b P_{O, j}\right)} \frac{u-Q_{O, j}}{2\left(a-b P_{O, i}\right)} \frac{1}{2\left(a-b P_{O, i}\right)} d u d t .
$$

When:

$$
\int_{0}^{Q_{O, i}} \frac{Q_{0, i}-t}{2\left(a-b P_{0, i}\right)} d t<\phi \int_{Q_{O, j}}^{2\left(a-b P_{o, j}\right)} \frac{u-Q_{O, j}}{2\left(a-b P_{O, j}\right)} d u
$$

the expected demand shift is:

$$
\int_{0}^{Q_{O, i}} \int_{Q_{O, j}}^{2\left(a-b P_{O, j}\right)} \frac{1}{2\left(a-b P_{o, j}\right)} \frac{Q_{o, i}-t}{2\left(a-b P_{o, i}\right)} d u d t .
$$

$j \equiv 3-i$ is defined, then the retailer's profit under off-invoice policy is given by Eq. (1) as shown in Box I.

The manufacturer $i$ 's profit under off-invoice policy is given by:

$$
\Pi_{M_{O, i}}=\left(W_{O, i}-\alpha-c\right) Q_{O, i}
$$

For scan-back policy, the manufacturer offered a per-unit discount to the retailer for each unit sold to consumers under the scan-back policy. The expected demand shift from channel $j$ to channel $i$ in the scanback case is:

$$
\phi \int_{0}^{Q_{S, i}} \int_{Q_{S, j}}^{2\left(a-b P_{S, j}\right)} \frac{u-Q_{S, j}}{2\left(a-b P_{S, j}\right)} \frac{1}{2\left(a-b P_{S, i}\right)} d u d t
$$

when:

$$
\int_{0}^{Q_{S, i}} \frac{Q_{S, i}-t}{2\left(a-b P_{S, i}\right)} d t \geq \phi \int_{Q_{S, j}}^{2\left(a-b P_{s, j}\right)} \frac{u-Q_{S, j}}{2\left(a-b P_{S, j}\right)} d u .
$$

The expected demand shift from channel $j$ to channel $i$ is:

$$
\int_{0}^{Q_{S, i}} \int_{Q_{S, j}}^{2\left(a-b P_{S, j}\right)} \frac{1}{2\left(a-b P_{S, j}\right)} \frac{Q_{S, i}-t}{2\left(a-b P_{S, i}\right)} d u d t
$$

when:

$$
\int_{0}^{Q_{S, i}} \frac{Q_{S, i}-t}{2\left(a-b P_{S, i}\right)} d t<\phi \int_{Q_{S, j}}^{2\left(a-b P_{S, j}\right)} \frac{u-Q_{S, j}}{2\left(a-b P_{S, j}\right)} d u .
$$

The retailer's profit under scan-back policy is given by Eq. (3) as shown in Box II.

The manufacturer $i$ 's profit under scan-back policy is given by Eq. (4) as shown in Box III.

For buy-back policy, the retailer is allowed to return unsold products to the manufacturer at an agreed price (i.e., buy-back policy). In this case, the expected demand shifting from channel $j$ to channel $i$ is:

$$
\phi \int_{0}^{Q_{B, i}} \int_{Q_{S, j}}^{2\left(a-b P_{B, j}\right)} \frac{u-Q_{B, j}}{2\left(a-b P_{B, j}\right)} \frac{1}{2\left(a-b P_{B, i}\right)} d u d t
$$

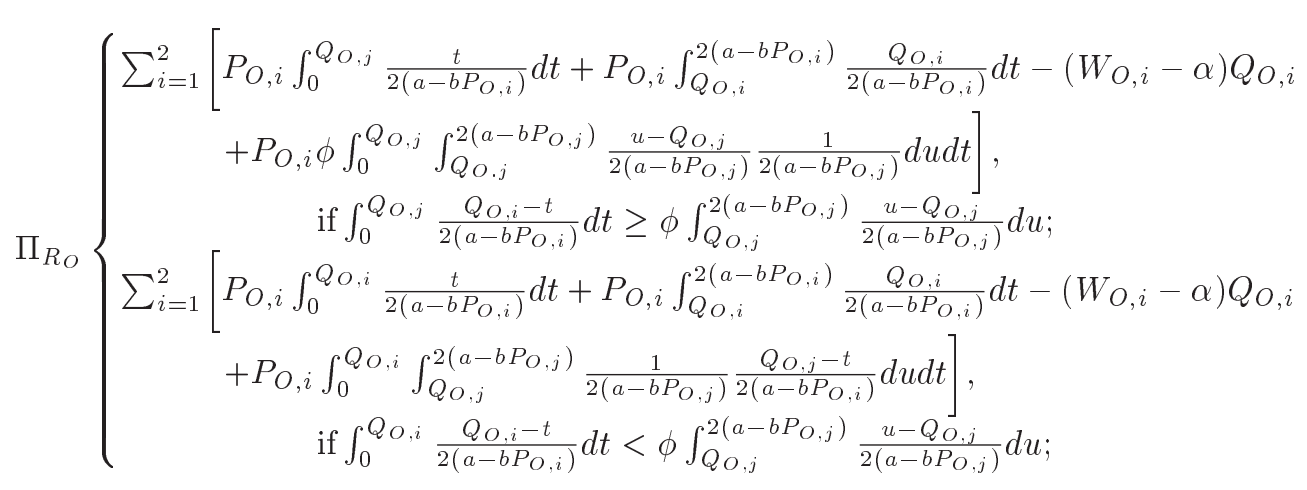




$$
\Pi_{R_{S}}\left\{\begin{array}{c}
\sum_{i=1}^{2}\left[\left(P_{S, i}+\beta\right) \int_{0}^{Q_{S, i}} \frac{t}{2\left(a-b P_{S, j}\right)} d t+\left(P_{S, i}+\beta\right) \int_{Q_{S, i}}^{2\left(a-b P_{S, i}\right)} \frac{Q_{S, i}}{2\left(a-b P_{S, i}\right)} d t-W_{S, i} Q_{S, i}\right. \\
\left.+\left(P_{S, i}+\beta\right) \phi \int_{0}^{Q_{S, i}} \int_{Q_{S, j}}^{2\left(a-b P_{S, j}\right)} \frac{u-Q_{S, j}}{2\left(a-b P_{S, j}\right)} \frac{1}{2\left(a-b P_{S, i}\right)} d u d t\right] \\
\quad \text { if } \int_{0}^{Q_{S, i}} \frac{Q_{S, i}-t}{2\left(a-b P_{S, i}\right)} d t \geq \phi \int_{Q_{S, j}}^{2\left(a-b P_{S, j}\right)} \frac{u-Q_{S, j}}{2\left(a-b P_{S, j}\right)} d u \\
\sum_{i=1}^{2}\left[\begin{array}{c}
\left(P_{S, i}+\beta\right) \int_{0}^{Q_{S, i}} \frac{t}{2\left(a-b P_{S, i}\right)} d t+\left(P_{S, i}+\beta\right) \int_{Q_{S, i}}^{2\left(a-b P_{S, i}\right)} \frac{Q_{S, i}}{2\left(a-b P_{S, i}\right)} d t-W_{S, i} Q_{S, i}, \\
+\left(P_{S, i}+\beta\right) \int_{0}^{Q_{S, i}} \int_{Q_{S, j}}^{2\left(a-b P_{S, j}\right)} \frac{1}{2\left(a-b P_{S, j}\right)} \frac{Q_{S, i}-t}{2\left(a-b P_{S, i}\right)} d u d t \\
\quad \text { if } \int_{0}^{Q_{S, i}} \frac{Q_{S, i}-t}{2\left(a-b P_{S, i}\right)} d t<\phi \int_{Q_{S, j}}^{2\left(a-b P_{S, j}\right)} \frac{u-Q_{S, j}}{2\left(a-b P_{S, j}\right)} d u .
\end{array}\right]
\end{array}\right.
$$

\section{Box II}

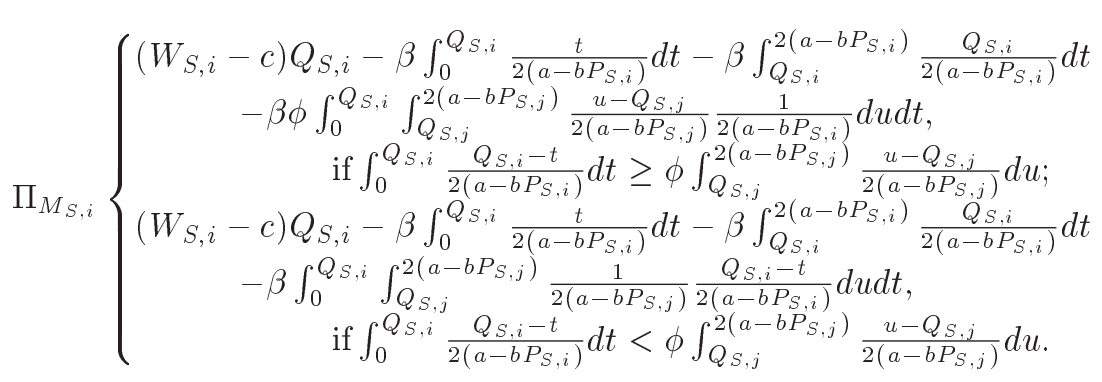

Box III

when:

$$
\int_{0}^{Q_{B, i}} \frac{Q_{B, i}-t}{2\left(a-b P_{B, i}\right)} d t \geq \phi \int_{Q_{B, j}}^{2\left(a-b P_{B, j}\right)} \frac{u-Q_{B, j}}{2\left(a-b P_{B, j}\right)} d u .
$$

The expected demand shift from channel $j$ to channel $i$ is:

$$
\int_{0}^{Q_{B, i}} \int_{Q_{B, j}}^{2\left(a-b P_{B, j}\right)} \frac{1}{2\left(a-b P_{B, j}\right)} \frac{Q_{B, i}-t}{2\left(a-b P_{B, i}\right)} d u d t
$$

when:

$$
\int_{0}^{Q_{B, i}} \frac{Q_{B, i}-t}{2\left(a-b P_{B, i}\right)} d t<\phi \int_{Q_{B, j}}^{2\left(a-b P_{B, j}\right)} \frac{u-Q_{B, j}}{2\left(a-b P_{B, j}\right)} d u .
$$

The retailer profit under buy-back policy can be written in Eq. (5) as shown in Box IV.

The manufacturer's profit under buy-back policy can be written in Eq. (6) as shown in Box V.

In the three trade promotion policies, retailer's profits are formulated as piecewise non-linear problems, because two cases may occur for each trade promotion policy. The first case (Case 1) is when the expected amount of customer demand willing to shift from another channel is larger than the expected surplus supply quantity, i.e.:

$$
\int_{0}^{Q_{O, i}} \frac{Q_{O, i}-t}{2\left(a-b P_{O, i}\right)} d t \geq \phi \int_{Q_{O, j}}^{2\left(a-b P_{O, j}\right)} \frac{u-Q_{O, j}}{2\left(a-b P_{O, j}\right)} d u,
$$

$$
\int_{0}^{Q_{S, i}} \frac{Q_{S, i}-t}{2\left(a-b P_{S, i}\right)} d t \geq \phi \int_{Q_{S, j}}^{2\left(a-b P_{S, j}\right)} \frac{u-Q_{S, j}}{2\left(a-b P_{S, j}\right)} d u
$$

or:

$$
\int_{0}^{Q_{B, j}} \frac{Q_{B, i}-t}{2\left(a-b P_{B, i}\right)} d t \geq \phi \int_{Q_{B, j}}^{2\left(a-b P_{B, j}\right)} \frac{u-Q_{B, j}}{2\left(a-b P_{B, j}\right)} d u .
$$

The second case (Case 2) is when the expected surplus supply quantity is larger than the expected amount of customer demand willing to shift from another channel, i.e.:

$$
\begin{aligned}
& \int_{0}^{Q_{O, i}} \frac{Q_{O, i}-t}{2\left(a-b P_{O, i}\right)} d t<\phi \int_{Q_{O, j}}^{2\left(a-b P_{O, j}\right)} \frac{u-Q_{O, j}}{2\left(a-b P_{O, j}\right)} d u \\
& \int_{0}^{Q_{S, i}} \frac{Q_{S, i}-t}{2\left(a-b P_{S, i}\right)} d t<\phi \int_{Q_{S, j}}^{2\left(a-b P_{S, j}\right)} \frac{u-Q_{S, j}}{2\left(a-b P_{S, j}\right)} d u,
\end{aligned}
$$




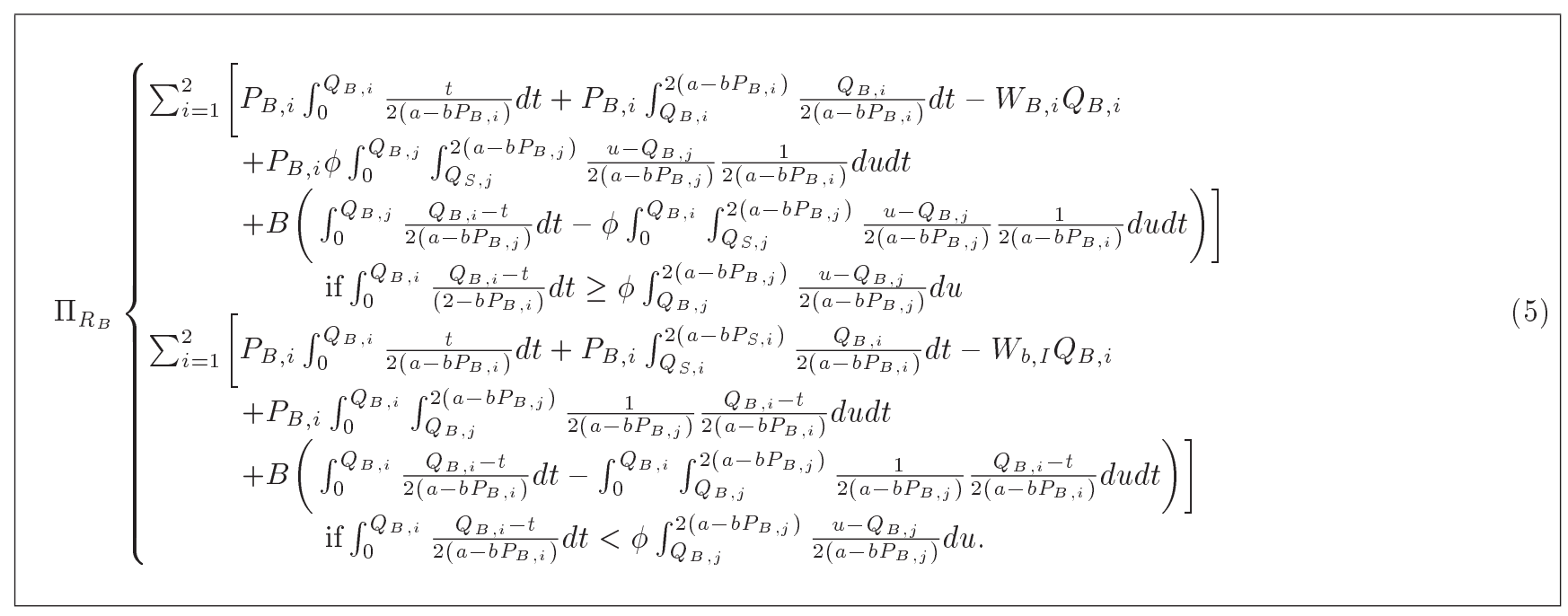

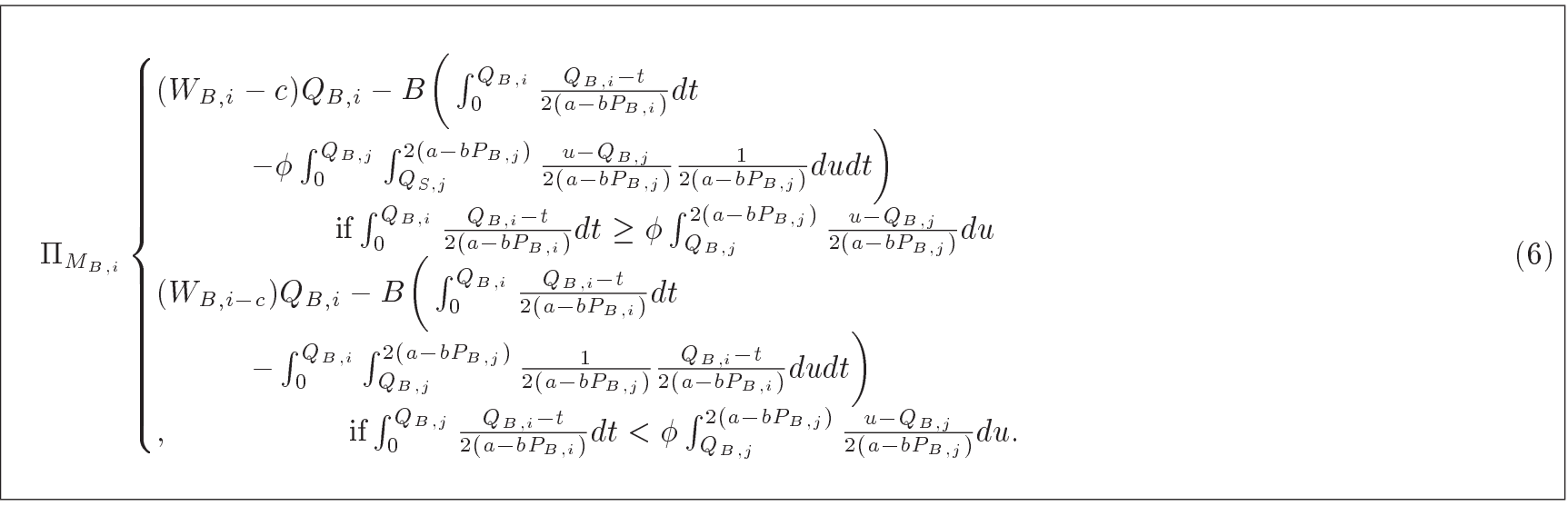

Box V

or:

$$
\begin{aligned}
\int_{0}^{Q_{B, i}} & \frac{Q_{B, i}-t}{2\left(a-b P_{B, i}\right)} d t \\
& <\phi \int_{Q_{B, j}}^{2\left(a-b P_{B, j}\right)} \frac{u-Q_{B, j}}{2\left(a-b P_{B, j}\right)} d u
\end{aligned}
$$

To solve the retailer's piecewise non-linear problem, we first determine the maximal profit $\Pi_{R}^{1}$ for Case 1 and $\Pi_{r}^{2}$ for Case 2. Then, the optimal decisions are chosen for the maximal profit $\Pi_{R}$, i.e. $\Pi_{R}^{*}=$ $\max \left\{\Pi_{R}^{1}, \Pi_{R}^{2}\right\}$.

For each model (trade promotion policy), the manufacturers determine the optimal wholesale prices, and the retailer determines the optimal retail price and order quantity to maximize their own profits. We use the following solution procedure to solve the problem. To determine the optimal wholesale price, we start with an initial guess of wholesale price. Given the wholesale price, the retailer determines the optimal retail prices and order quantities to maximize his profit for different brands. Consequently, the manufacturer's profit can be calculated. Then, we choose an error tolerance and set a new wholesale price as the sum of the original wholesale price and the error tolerance. Given the new wholesale price, the optimal retail prices and order quantities for different brands can be determined. We can also compute the manufacturer's profit based on the new wholesale price. If the manufacturer's profit with the new wholesale price is larger than that with the original wholesale price, set another new wholesale price (the sum of the new wholesale price and the error tolerance) and determine retailer's decisions and manufacturer's profits. Otherwise, set another new wholesale price to be the value of subtracting the error tolerance from the new wholesale price and determine retailer's decisions and manufacturer's profits. Repeat these processes until the manufacturer's profit decreases for the first time. Thus, we can determine the optimal wholesale prices, retail prices, and order quantities under brand competition. The following 
algorithm shows the solving process.

\section{Algorithm}

- Step 1. Set an initial guess for wholesale price, $W_{0}$, and an error tolerance $\varepsilon$.

- Step 2. Determine $P_{0}^{*}$ and $Q_{0}^{*}$ to maximize $\Pi_{R}\left(P_{0}, Q_{0} \mid W_{0}\right)$.

- Step 3. Let $W_{k=1}=W_{0}+\varepsilon$, determine $P_{k=1}^{*}$ and $Q_{k=1}^{*}$ to maximize $\Pi_{R}\left(P_{1}, Q_{1} \mid W_{1}\right)$.

- Step 4. If $\Pi_{M}\left(P_{1}, Q_{1} \mid W_{1}\right) \geq \Pi_{M}\left(P_{0}, Q_{0} \mid W_{0}\right)$, go to Step 5; otherwise, go to Step 6.

\section{- Step 5.}

- Step 5.1. Let $W_{k+1}=W_{k}+\varepsilon$, determine $P_{K+1}^{*}$ and $Q_{k+1}^{*}$ to maximize $\Pi_{R}\left(P_{k+1}, Q_{k+1} \mid W_{k+1}\right)$.

- Step 5.2. If:

$$
\Pi_{M}\left(P_{k+1}, Q_{k+1} \mid W_{k+1}\right) \geq \Pi\left(P_{k}, Q_{k} \mid W_{k}\right),
$$

let: $k=k+1$ and go to Step 5.1; otherwise, set:

$$
\begin{aligned}
& W^{*}=W_{k}, \quad P^{*}=P_{k}, \\
& Q^{*}=Q_{k}, \quad \Pi_{M}^{*}=\Pi_{M}\left(\mid W_{k}, P_{k}, Q_{k}\right),
\end{aligned}
$$

and:

$$
\Pi_{R}^{*}=\Pi_{R}\left(\mid W_{k}, P_{k}, Q_{k}\right),
$$

and then stop.

\section{- Step 6.}

- Step 6.1. Let $W_{k+1}=W_{k}-\varepsilon$, determine $P_{k+1}^{*}$ and $Q_{K+1}^{*}$ to maximize $\Pi_{R}\left(P_{k+1}, Q_{k+1} \mid W_{k+1}\right)$.

- Step 6.2. If:

$$
\Pi_{M}\left(P_{k+1}, Q_{k+1} \mid W_{k+1}\right) \geq \Pi_{M}\left(P_{k}, Q_{k} \mid W_{k}\right),
$$

let $k=k+1$ and go to Step 6.1; Otherwise, set:

$$
\begin{aligned}
& W^{*}=W_{k} \quad, P^{*}=P_{k}, \\
& Q^{*}=Q_{k}, \quad \Pi_{M}^{*}=\Pi_{M}\left(\mid W_{k}, P_{k}, Q_{k}\right)
\end{aligned}
$$

and:

$$
\Pi_{R}^{*}=\Pi_{R}\left(\mid W_{k}, P_{k}, Q_{k}\right)
$$

and then stop.

\section{Numerical analysis}

In this section, we conduct a numerical analysis to realize the effectiveness of each trade promotion, and how trade promotion and substitution rate affect decisions and profits. Tables 1 to 3 show the manufacturers' and retailer's decisions and profits with different substitution rate under the three trade promotions.

\begin{tabular}{|c|c|c|c|c|c|c|}
\hline $\begin{array}{c}\text { Rate of } \\
\text { substitution } \\
\phi \\
\end{array}$ & $\begin{array}{c}\text { Trade } \\
\text { promotion } \\
\alpha \alpha \\
\end{array}$ & $\begin{array}{c}\text { Wholesale } \\
\text { price } \\
W_{o, i}=W_{o, j}\end{array}$ & $\begin{array}{c}\text { Retail } \\
\text { price } \\
P_{o, i}=P_{o, j}\end{array}$ & $\begin{array}{c}\text { Order } \\
\text { quantity } \\
Q_{O, i}=Q_{O, j}\end{array}$ & $\begin{array}{c}\text { Manufacturer } \\
\text { profits } \\
\Pi_{M_{O, i}}=\Pi_{M_{O, j}}\end{array}$ & $\begin{array}{c}\text { Retailer } \\
\text { profit } \\
\Pi_{R_{0}} \\
\end{array}$ \\
\hline \multirow{3}{*}{0} & 1.5 & 7.78 & 14.37 & 31.70 & 167.35 & 256.42 \\
\hline & 2 & 8.28 & 14.37 & 31.70 & 167.35 & 256.42 \\
\hline & 2.5 & 8.78 & 14.37 & 31.70 & 167.35 & 256.42 \\
\hline \multirow{3}{*}{0.15} & 1.5 & 7.94 & 14.28 & 30.22 & 164.42 & 260.26 \\
\hline & 2 & 8.44 & 14.28 & 30.22 & 164.42 & 260.26 \\
\hline & 2.5 & 8.94 & 14.28 & 30.22 & 164.42 & 260.26 \\
\hline \multirow{3}{*}{0.3} & 1.5 & 8.15 & 14.21 & 28.69 & 162.10 & 262.91 \\
\hline & 2 & 8.65 & 14.21 & 28.69 & 162.10 & 262.91 \\
\hline & 2.5 & 9.15 & 14.21 & 28.69 & 162.10 & 262.91 \\
\hline \multirow{3}{*}{0.45} & 1.5 & 8.42 & 14.16 & 27.11 & 160.51 & 263.94 \\
\hline & 2 & 8.92 & 14.16 & 27.11 & 160.51 & 263.94 \\
\hline & 2.5 & 9.42 & 14.16 & 27.11 & 160.51 & 263.94 \\
\hline
\end{tabular}
We analyze the effect of substitution rate, $\phi$, on the results. We assume symmetric wholesale prices, retail prices, and order quantity in order to compare the three trade promotions (off-invoice, scan-back, and buy-back) directly. We have the following numerical results:

Table 1. Optimal decisions under off-invoice and substitution effect $(a=100 ; b=5 ; c=1)$ 
Table 2. Optimal decisions under scan-back and substitution effect $(a=100 ; b=5 ; c=1)$.

\begin{tabular}{|c|c|c|c|c|c|c|}
\hline $\begin{array}{c}\text { Rate of } \\
\text { substitution } \\
\phi \\
\end{array}$ & $\begin{array}{c}\text { Trade } \\
\text { promotion } \\
\beta\end{array}$ & $\begin{array}{c}\text { Wholesale } \\
\text { price } \\
W_{S, i}=W_{S, j}\end{array}$ & $\begin{array}{c}\text { Retail } \\
\text { price } \\
P_{S, i}=P_{S, j}\end{array}$ & $\begin{array}{c}\text { Order } \\
\text { quantity } \\
Q_{S, i}=Q_{S, j}\end{array}$ & $\begin{array}{c}\text { Manufacturer } \\
\text { profits } \\
\Pi_{M_{S, i}}=\Pi_{M_{S, j}}\end{array}$ & $\begin{array}{c}\text { Retailer } \\
\text { profit } \\
\Pi_{R_{S}} \\
\end{array}$ \\
\hline \multirow{3}{*}{0} & 1.5 & 7.43 & 14.30 & 30.18 & 160.79 & 252.74 \\
\hline & 2 & 7.82 & 14.28 & 29.71 & 158.67 & 251.47 \\
\hline & 2.5 & 8.22 & 14.27 & 29.23 & 156.58 & 249.78 \\
\hline \multirow{3}{*}{0.15} & 1.5 & 7.66 & 14.21 & 28.61 & 157.40 & 255.78 \\
\hline & 2 & 8.08 & 14.19 & 28.09 & 155.14 & 253.95 \\
\hline & 2.5 & 8.51 & 14.18 & 27.56 & 152.92 & 251.76 \\
\hline \multirow{3}{*}{0.3} & 1.5 & 7.96 & 14.14 & 26.96 & 154.76 & 256.99 \\
\hline & 2 & 8.41 & 14.12 & 26.42 & 152.41 & 254.78 \\
\hline & 2.5 & 8.86 & 14.10 & 25.92 & 150.10 & 252.79 \\
\hline \multirow{3}{*}{0.45} & 1.5 & 8.31 & 14.09 & 25.40 & 152.97 & 257.58 \\
\hline & 2 & 8.78 & 14.07 & 24.89 & 150.56 & 255.62 \\
\hline & 2.5 & 9.27 & 14.06 & 24.35 & 148.20 & 252.90 \\
\hline
\end{tabular}

Table 3. Optimal decisions under buy-back and substitution effect $(a=100 ; b=5 ; c=1)$.

\begin{tabular}{|c|c|c|c|c|c|c|}
\hline $\begin{array}{c}\text { Rate of } \\
\text { substitution } \\
\phi \\
\end{array}$ & $\begin{array}{c}\text { Trade } \\
\text { promotion } \\
B\end{array}$ & $\begin{array}{c}\text { Wholesale } \\
\text { price } \\
W_{B, i}=W_{B, j}\end{array}$ & $\begin{array}{c}\text { Retail } \\
\text { price } \\
\boldsymbol{P}_{B, i}=\boldsymbol{P}_{B, j}\end{array}$ & $\begin{array}{c}\text { Order } \\
\text { quantity } \\
Q_{B, i}=Q_{B, j}\end{array}$ & $\begin{array}{c}\text { Manufacturer } \\
\text { profits } \\
\Pi_{M_{B, i}}=\Pi_{M_{B, j}}\end{array}$ & $\begin{array}{c}\text { Retailer } \\
\text { profit } \\
\Pi_{R_{B}}\end{array}$ \\
\hline \multirow{3}{*}{0} & 1.5 & 6.67 & 14.44 & 33.37 & 174.16 & 259.41 \\
\hline & 2 & 6.82 & 14.48 & 33.89 & 176.47 & 259.53 \\
\hline & 2.5 & 6.97 & 14.51 & 34.48 & 178.78 & 259.88 \\
\hline \multirow{3}{*}{0.15} & 1.5 & 6.77 & 14.36 & 32.01 & 171.76 & 263.83 \\
\hline & 2 & 6.90 & 14.39 & 32.60 & 174.25 & 264.26 \\
\hline & 2.5 & 7.03 & 14.42 & 33.26 & 176.77 & 264.97 \\
\hline \multirow{3}{*}{0.3} & 1.5 & 6.91 & 14.29 & 30.56 & 169.82 & 267.21 \\
\hline & 2 & 7.02 & 14.32 & 31.17 & 172.46 & 267.80 \\
\hline & 2.5 & 7.13 & 14.35 & 31.86 & 175.12 & 268.71 \\
\hline \multirow{3}{*}{0.45} & 1.5 & 7.10 & 14.23 & 29.02 & 168.49 & 269.10 \\
\hline & 2 & 7.18 & 14.26 & 29.69 & 171.23 & 270.31 \\
\hline & 2.5 & 7.27 & 14.30 & 30.38 & 174.00 & 271.26 \\
\hline
\end{tabular}

1. For the three trade promotion policies, when the substitution rate, $\phi$, increases, the wholesale price and retailer's profit will increase, but the retail price, order quantity, and manufacturer profit will decrease. Increasing brand substitution effect means that customers are willing to buy another brand when they cannot find their preferred brand in the same retail store. Therefore, the retailer's profit will increase as brand substitution effect increases. It is reasonable for a retailer to decrease order quantities for each brand, because customers will buy another brand in the same store if their 


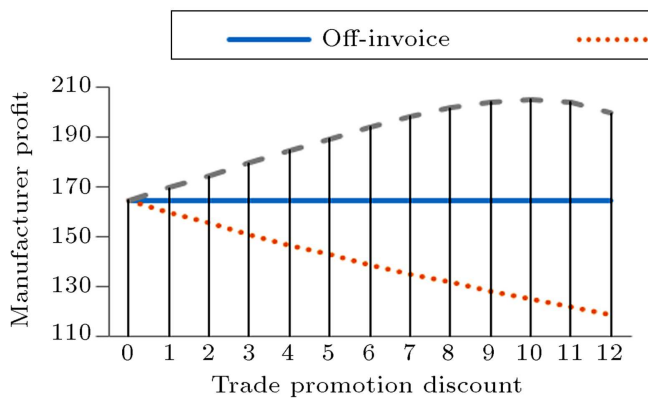

(a)

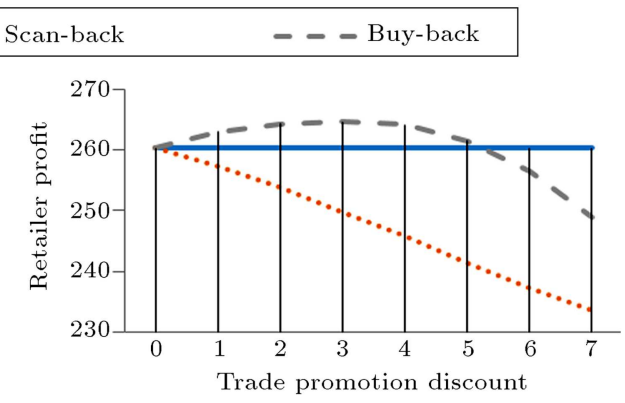

(b)

Figure 1. Profits under different trade promotion (when $\phi=0.15$ ).

preferred brand is in shortage;

2. For the off-invoice policy, when the trade promotion discount increases, the wholesale price will increase; but the retail price, order quantity, manufacturer's profit, and retailer's profit will not change. For the scan-back policy, when the trade promotion discount increases, the wholesale price will increase; but the retail price, order quantity, manufacturer profit, and retailer profit will decrease. For the buy-back policy, when the trade promotion discount increases, the wholesale price will increase; but the retail price, order quantity, manufacturer profit, and retailer profit will increase;

3. Compare the three trade promotion policies, wholesale price is the lowest; retail price and order quantity are the highest under the buy-back policy. Wholesale price is the highest under the off-invoice policy; retail price and order quantity are the lowest under the scan-back policy. Profits of the manufacturer and retailer are the highest in the buy-back policy. Actually, profits of the manufacturer and retailer are concave as the buy-back price. Take $\phi=0.15$ as an example, Figure 1 shows the profits under different trade promotions. It shows that the profits of both the manufacturer and retailer under the buy-back policy are higher than those under the off-invoice and scan-back policies, when the buyback price is determined within an appropriative range.

\section{Conclusion}

This paper considers a two-echelon supply chain where two competing manufacturers sell products to a single retailer and the retailer sells products to end customers. The manufacturers provide trade promotions to a retailer, and the retailer faces uncertain and pricedependent end customer demand. The objective is to determine the optimal wholesale prices to maximize manufacturers' profits and the optimal retail price and order quantity to maximize retailer's profit. An algorithm is provided to solve the problem. We consider three trade promotions (off-invoice, scan-back, and buy-back) and compare their performances. The results indicate that the manufacturers and retailers prefer the buy-back policy over the off-invoice and scanback policies under brand competition and demand uncertainty. The wholesale prices and retailer's profit will increase, but the retail price, order quantity, and manufacturers' profits will decrease as the brand substitution effect increases. This study also shows that wholesale price is the lowest; retail price and order quantity are the highest in buy-back policy. Perhaps surprisingly, retail price and order quantity will decrease as scan-back trade promotion discount increases; they will remain unchanged as off-invoice trade promotion discount increases; they will increase as buy-back trade promotion discount increases.

This paper contributes to the literature in several ways. First, based on our research, this is the first study to consider trade promotions under brand competition and demand uncertainty. We also made the optimal pricing and ordering decisions for manufacturers and retailers in a two-echelon supply chain. A solution approach was proposed for solving the resulting non-linear programs in this study. Third, we conducted numerical studies to demonstrate the solution procedures and determined the effects of the relevant model parameters on manufacturers' and retailer's decisions and profits. The results and the modeling approach are useful references for managerial decisions. Suggestions for further research are provided as follows: First, the model can be extended to consider both brand and retailer competitions. Second, it should be discussed how other trade promotions affect the channel behavior would be also worthwhile.

\section{Acknowledgement}

The author expresses his gratitude to the editor and the anonymous reviewers for their detailed comments and valuable suggestions to improve the exposition of this paper. This paper is supported in part by the Ministry of Science and Technology under Grant MOST 1042221-E-011 -171 -MY3. 


\section{References}

1. Tsao, Y.C., Teng, W.G., Chen, R.S. and Chou, W.Y. "Pricing and inventory policies for Hi-tech products under replacement warranty", International Journal of System Science, 45(6), pp. 1255-1267 (2014).

2. Modak, N.M., Panda, S. and Sana, S.S. "Pricing policy and coordination for a distribution channel with manufacturer suggested retail price", International Journal of Systems Science: Operations $\&$ Logistics, 3, pp. 92-101 (2015).

3. Ouyang, L.Y., Ho, C.H. and Su, C.H. "An optimization approach for joint pricing and ordering problem in an integrated inventory system with ordersize dependent trade credit", Computers \& Industrial Engineering, 57, pp. 920-930 (2009).

4. Sajadieh, M.S. and Jokar, M.R.A. "Optimizing shipment, ordering and pricing policies in a two-stage supply chain with price-sensitive demand", Transportation Research Part E: Logistics and Transportation Review, 45, pp. 564-571 (2009).

5. Sana, S.S. "The stochastic EOQ model with random sales price", Applied Mathematics and Computation, 218(2), pp. 239-248 (2011).

6. Cai, G., Chiang, W.C. and Chen, X. "Game theoretic pricing and ordering decisions with partial lost sales in two-stage supply chains", International Journal of Production Economics, 130, pp. 175-185 (2014).

7. Sana, S.S. "A collaborating inventory model in a supply chain", Economic Modelling, 29(5), pp. 20162023 (2012).

8. Hsieh, C.C., Chang, Y.L. and Wu, C.H. "Competitive pricing and ordering decisions in a multiple-channel supply chain", International Journal of Production Economics, 154, pp. 156-165 (2014).

9. Maihami, R. and Karimi, B. "Optimizing the pricing and replenishment policy for non-instantaneous deteriorating items with stochastic demand and promotional efforts", Computers \& Operations Research, 51, pp. 302-312 (2014).

10. Modak, N.M., Panda, S. and Sana, S.S. "Three-echelon supply chain coordination considering duopolistic retailers with perfect quality products", International Journal of Production Economics, (2015), doi:10.1016/j.ijpe.2015.05.021.

11. Panda, S., Modak, N.M., Sana, S.S. and Basu, M, "Pricing and replenishment policies in dual-channel supply chain under continuous unit cost decrease", Applied Mathematics and Computation, 256, pp. 913929 (2015).

12. Modak, N.M., Panda, S., Sana, S.S. and Basu, M. "Corporate social responsibility, coordination and profit distribution in a dual-channel supply chain",
Pacific Science Review (2015). doi:10.1016/j.pscr.2015. 05.001 .

13. Nijs, V., Misra, K., Anderson, E.T., Hansen, K. and Krishnamurthi, L. "Channel pass-through of trade promotions", Marketing Science, 29(2), pp. 250-267 (2010).

14. Yuan, H., Gòmez, M. and Rao, V.R. "Trade promotion decisions under demand uncertainty: A market experiment approach", Management Science, 59(7), pp. 1709-1724 (2013).

15. Krishnan, H., Kapuscinski, R.K. and Butz, D.A. "Coordinating contracts for decentralized supply chain with retailer promotional effect", Management Science, 50(1), pp. 48-62 (2004).

16. Chen, J. and Bell, P.C. "Coordinating a decentralized supply chain with customer returns and pricedependent stochastic demand using a buyback policy", European Journal of Operational Research, 212, pp. 293-300 (2011).

17. Wu, D. "Coordination of competing supply chains with news-vendor and buyback contract", International Journal of Production Economics, 144(1), pp. 1-13 (2013).

18. Zhao, Y.Z., Choi, T.M., Cheng, T.C.E., Sethi, S.P. and Wang, S. "Buyback contracts with price-dependent demands: Effects of demand uncertainty", European Journal of Operational Research, 239(3), pp. 663-673 (2014).

19. Cachon, G.P. and Kok, A.G. "Competing manufacturers in a retail supply chain: On contractual form and competition", Management Science, 56(3), pp. 571589 (2010).

20. Sana, S.S. and Goyal, S.K. "(Q, r, L) model for stochastic demand with lead-time dependent partial backlogging", Annals of Operations Research, (2014) DOI:10.1007/s10479-014-1731-2.

\section{Biography}

Yu-Chung Tsao is currently a Professor in the Department of Industrial Management at National Taiwan University of Science and Technology. Prior to his current position, he was an Associate Professor in the Sino-US Global Logistics Institute at Shanghai Jiao Tong University and in the Department of Business Management at Tatung University. He was a visiting scholar in the School of Industrial and Systems Engineering at Georgia Institute of Technology. His research interests are in the areas of decision sciences, supply chain management, optimization application, and business analytics. 